

\title{
Adolescentes Negros Moradores das Periferias Urbanas do Rio de Janeiro: entre Escola, Gênero, Masculinidades, Raça, Violência e Vivências
}

\author{
Adolescentes Negros Abitantes de las Periferias Urbanas de Río de Janeiro: \\ Entre Escuela, Género, Masculinidades, Raza, Violencia y Vivencias
}

\author{
Black Adolescents Living on the Outskirts of Rio de Janeiro: Between School, \\ Gender, Masculinities, Race, Violence and Life Experiences
}

\section{Resumo}

Este artigo se propõe a discutir como os jovens adolescentes negros do $9^{\circ}$ ano de uma escola pública de Duque de Caxias, periferia urbana do Rio de Janeiro, se co/constroem como homens e como vivenciam suas masculinidades em seu cotidiano. Para atingirmos os objetivos propostos, realizamos como atividade extraclasse uma roda de conversa com quatro alunos negros, a fim de conhecermos suas histórias e, a partir delas, buscarmos compreender como se constroem como homens negros, criando significados sobre a masculinidade legitimada e reconhecida pelo senso comum. O pensamento decolonial iluminou nossa reflexão. Como metodologia de pesquisa, nos inspiramos nas dinâmicas possibilitadas pelo grupo focal, subsidiados pelos estudos de Gondin (2003) e Morgan (1997). O estudo com o grupo de adolescentes negros apontou para a necessidade do estabelecimento de políticas educacionais de gênero e saúde voltadas para este segmento.

Palabras-Clave: Adolescentes; Gênero; Masculinidades; Raça; Sexualidades.

\section{Resumen}

Este artículo se propone discutir cómo jóvenes adolescentes negros del $9^{\circ}$ año de una escuela pública de Duque de Caxias, periferia urbana de Río de Janeiro, se co-construyen como hombres y cómo vivencian sus masculinidades en su cotidiano. Para alcanzar los objetivos propuestos, realizamos como actividad extraescolar una conversación con cuatro alumnos negros, con el fin de conocer sus historias y, a partir de ellas, comprender cómo se construyen como hombres negros, creando significados sobre la masculinidad legitimada y reconocida por el sentido común. El pensamiento decolonial iluminó nuestra reflexión. Como metodología de investigación, nos inspiramos en las dinámicas posibilitadas por el grupo focal, basadas los estudios de Gondin (2003) y Morgan (1997). El estudio con el grupo de adolescentes negros evidenció la necesidad del establecimiento de políticas educativas de género y salud dirigidas a este colectivo.

Palavras-chave: Adolescentes; Género; Masculinidades; Carrera. Sexualidades.

Paulo Melgaço da Silva Junior, Leandro da Conceição Borges 
Adolescentes Negros Moradores das Periferias Urbanas do Rio de Janeiro:

Entre Escola, Gênero, Masculinidades, Raça, Violência e Vivências

\begin{abstract}
This article proposes to discuss how young black male adolescents in the 9th grade of a public school in Duque de Caxias, on the outskirts of Rio de Janeiro, mutually build themselves up as men and how they experience their masculinities in their daily lives. In order to achieve the proposed objectives, we conducted as an extra class activity, a conversation round with four black male students, in order to hear their stories and, from them, we sought to understand how they build up themselves as black men, creating meanings about a masculinity that is legitimized and recognized by the common senses. Decolonial thinking enlightened our reflections. With regard to research methodology, we were inspired by the dynamics made possible by the focus group, supported by the studies of Gondin (2003) and Morgan (1997). The study with the black male adolescents group pointed to the need to establish gender and health education policies focused on this segment.
\end{abstract}

Keywords: Adolescents; Gender; Masculinities; Race; Sexualities.

A carne mais barata do mercado é a carne negra... Que vai de graça pro presídio... E para debaixo do plástico... Que vai de graça pro subemprego... E pros hospitais psiquiátricos.

Elza Soares

\title{
Introdução
}

As questões relativas à raça, gênero e classe social estão imbricadas e têm relação direta com os processos de hierarquização social. Isto faz com que, a todo o momento, sejamos interpelados e classificados a partir das expectativas com que estas subjetividades são criadas em outros sujeitos sociais, estabelecendo um conjunto de normatizações em torno do direito à vida e à cidadania.

Segundo o 'Atlas da violência 2017', negros e jovens são as maiores vítimas da violência. O documento indica que, “[...] dos 78,9\% dos indivíduos pertencentes ao grupo, $10 \%$ [têm] mais chances de serem vítimas fatais. [...] Jovens e negros do sexo masculino continuam sendo assassinados todos os anos como se vivessem em situação de guerra". (ATLAS DA VIOLÊNCIA, 2017, p. 30).

Nesta perspectiva, a carne negra destes jovens está no mercado e nos revela como os processos de colonização que construíram e subalternizaram o homem negro ainda estão presentes em nossa sociedade, contribuindo para a sedimentação de uma identidade do macho negro. A partir dela, ele é visto como forte e pouco inteligente, o que o tornaria biologicamente apto para o trabalho braçal e a prática de esportes, além de sexualmente bem-dotado e sempre pronto para o ato sexual:

Os homens negros são o grupo sócio-racial menos escolarizado, temos um ingresso mais tardio na rede de ensino, uma saída mais precoce, um nível de aproveitamento ruim, acentuada distorção sérieidade, assim como um baixo retorno aos bancos escolares em idade

Paulo Melgaço da Silva Junior, Leandro da Conceição Borges 
Adolescentes Negros Moradores das Periferias Urbanas do Rio de Janeiro:

Entre Escola, Gênero, Masculinidades, Raça, Violência e Vivências

adiantada. Além disso, possuímos baixíssimos índices de acesso ao ensino superior na graduação e na pós-graduação. Uma das possíveis respostas para esse fenômeno seria a sequência de mecanismos discriminatórios mobilizados quando um menino negro entra na escola e lá permanece. Discursos subalternizantes da história, cultura e estética africana e afro-brasileira em sala de aula, material didático com imagens estereotipadas de homens e mulheres negras, aliados à maior rigidez, desinteresse e insensibilidade do corpo administrativo ao lidar com esse menino, constituem-se como um "método" para o fracasso educacional desse grupo. Quando não, o simples e cru xingamento racial se torna uma eficiente ferramenta para imobilizar seu alvo nos momentos das desavenças e competições (SOUZA, 2017a, s/p).

Os corpos na escola se apresentam alheios às questões da sexualidade e da raça. A escola se encarregou (e ainda se encarrega) de negligenciá-los e desrepresentá-los, ignorando prazeres e desejos, dado que é a cognição que ocupa destaque nas salas de aula. Contudo, mesmo que a escola contribua para um apagamento do corpo, podemos pensá-la como produtora de identidades corporificadas, produzindo e reproduzindo corpos generificados, sexualizados e racializados.

Tal noção ratifica a necessidade de se conhecer o pensamento destes jovens, tematizando e problematizando as questões que emergem do cotidiano das escolas. Embora os temas masculinidades, raça, gênero, sexualidades e classe social já se mostrem presentes nos debates em âmbito escolar, ainda encontramos grandes desafios para que possam transpor os muros escolares e serem efetivamente problematizados nas relações cotidianas.

Parte do problema advém do fato de os/as docentes terem grande dificuldade em abordar estas questões em sala de aula. Assim, ao deslocarem o tema da sexualidade para o campo da vida privada, descontextualizando os debates em torno das questões raciais e de classe social, tais profissionais acabam por invisibilizar importantes percepções, o que resulta em consequências sociopolíticas e culturais mais amplas.

É relevante ressaltar que Gomes e Silva (2017), Silva et al. (2012), Chimin Junior (2009) destacam que o espaço é um elemento fundamental para compreender a vulnerabilidade dos meninos adolescentes negros e que as desigualdades das cidades acabam por tirar destes jovens algumas possibilidades de ascensão. Ao mesmo tempo, de acordo com Chimin Junior (2009) o espaço pode auxiliar nas fugas das explicações generalizantes que pouco colaboram com o processo de formulação de políticas e execução de ações públicas. $\mathrm{O}$ autor também destaca que tal compreensão pode adquirir significados diferentes para cada grupo social. Assim, podemos compreender múltiplas vivências mediadas por relações de poder que colocam o mesmo sujeito social em diferentes posições. Nas palavras do autor, "um sujeito pode estar relacionado ao espaço familiar onde suas relações de poder o coloca em posição periférica em determinado momento. Ao mesmo tempo em um grupo

Paulo Melgaço da Silva Junior, Leandro da Conceição Borges 
Adolescentes Negros Moradores das Periferias Urbanas do Rio de Janeiro:

Entre Escola, Gênero, Masculinidades, Raça, Violência e Vivências

de adolescentes onde suas relações de poder o coloca em posição central" (CHIMIN JUNIOR, 2009, p.47). Com isso as relações com o espaço e tempo podem mudar constantemente e envolver diferentes escalas de relação.

Neste artigo nos interessa pensar as experiências dos adolescentes que moram nas periferias urbanas. Defendemos que este estudo abre possibilidades de se conhecer como determinados discursos e conceitos que circulam nos grandes centros são apropriados e reinventados nestes espaços. Neles, as relações de vizinhança persistem muito mais do que em bairros de classe média ou alta, fazendo com que as necessidades básicas e os espaços de sociabilidade redesenhem novas formas de perceber o mundo social. (SILVA JUNIOR; MOREIRA, 2010).

Gomes e Silva (2017) apresentam a periferia urbana como um espaço que se faz e desfaz constantemente de relações específicas, a partir das interseções de idade, raça, gênero e atravessadas simultaneamente por múltiplas escalas. Assim ser jovem, homem, negro, morador de periferia significa estar marcado por constantes relações de poder que o reposiciona constantemente frente a outros sujeitos sociais.

Neste sentido, o objetivo central deste texto é discutir como jovens adolescentes negros do $9^{\circ}$ ano de uma escola pública de Duque de Caxias, periferia urbana do Rio de Janeiro, constroem suas masculinidades nas vivências cotidianas. Para atingirmos os objetivos propostos, realizamos como atividade extraclasse uma roda de conversa com quatro alunos negros do $9^{\circ}$ ano (Pedro, Thiago Daniel e Lorran ${ }^{1}$ ), a fim de conhecermos suas histórias, e como vivenciam suas masculinidades em seu cotidiano.

Como encaminhamento metodológico, nos baseamos nos estudos de Gondin (2003) e Morgan (1997) para o desenvolvimento de dinâmicas. Estas foram subsidiadas pelo grupo focal, entendido como uma técnica de pesquisa que, ao propor a discussão de um tópico específico sugerido pelo pesquisador, tende a produzir dados por meio das interações grupais. Cabe ao entrevistador ouvir a opinião de membros do grupo, à medida que compara suas respostas, de modo a entrelaçar os pontos de vista e intensificar o diálogo. Assim, os autores destacam que a unidade de análise do grupo focal é o próprio grupo. Nele, se uma opinião é esboçada, mesmo não sendo compartilhada por todos, para efeito de análise e interpretação dos resultados ela é referida como coletiva. Deste modo, ela nos mostra que o ponto de partida para a realização do propósito é o entendimento dos objetivos propostos, o cuidado na escolha de participantes e as análises das entrevistas transcritas. Neste último ponto, foram levadas em consideração as contribuições dos estudos das masculinidades e decolonialidades.

A relevância deste estudo está ancorada na necessidade em se problematizar a implementação de políticas de gênero e saúde voltadas para os adolescentes, principalmente os negros, moradores das periferias urbanas, que venham a contar com a participação efetiva das escolas. Estas últimas, por sua vez, precisam buscar a inteligibilidade para todos os sujeitos, ao propor possibilidades de se pensar em vidas que não são ordinariamente pensadas ou reconhecidas como tais. Contudo, tal movimento não constitui introduzir um

1 Nome fictício..

Paulo Melgaço da Silva Junior, Leandro da Conceição Borges

Revista Latino-americana de Geografia e Gênero, Ponta Grossa, v. 9, n. 1, p. 3 - 21, jan. / jun. 2018. 
Adolescentes Negros Moradores das Periferias Urbanas do Rio de Janeiro:

Entre Escola, Gênero, Masculinidades, Raça, Violência e Vivências

novo conhecimento ao currículo por meio de uma disciplina específica. Nossa proposta é que estas discussões estejam presentes no fazer cotidiano dos/as professores/as. Acreditamos que a questão central seja problematizar o conhecimento inscrito, desestabilizando os binarismos $\mathrm{e}$ as verdades construídas sobre gênero, sexualidades, raça e classe.

No sentido de expor os caminhos e problemáticas suscitadas pela pesquisa, o artigo foi estruturado da seguinte maneira: "Entre colonialidade e decolonialidade" situa e contextualiza a violência dentro da sociedade, assim como a perspectiva de dominação/subordinação; Em "Quando o gênero, sexualidades, masculinidades e raça entram em questão", contempla-se a discussão sobre as quatro temáticas (gênero, sexualidades, raça e classe) como elementos historicamente norteadores para a construção máscula do homem negro na sociedade; "A escola, os sujeitos e os contextos do grupo focal" descreve o ambiente da escola que serviu de base para esta pesquisa, assim como os procedimentos metodológicos utilizados na pesquisa e a apresentação dos sujeitos participantes; As seções "Entre adolescentes negros", "Entre o neguinho e negão", "E as meninas?", "Força e violência", "Sobre homossexualidade e sexo com homens", "Sobre camisinha" discorrem sobre as opiniões dos entrevistados acerca de cada ponto levantado na pesquisa; por fim, as "conclusões" e as referências.

\section{Entre Colonialidade e Decolonialidade}

As questões de subalternização e hierarquização de determinadas subjetividades e as ações que justificam a violência contra o outro estão pautadas no processo de colonialidade ${ }^{2}$, que envolve as relações de poder que emergiram no contexto de colonialismo europeu na América, Ásia e África. (MIGNOLO, 2007). Entretanto, seus efeitos não estão limitados a este período histórico em específico, tendo deixado suas consequências físico-psicológicas nos modos como são projetados e concebidos os conhecimentos que acabaram por subalternizar a população negra, bem como nas subalternidades epistêmicas e racistas no Ocidente. Neste aspecto, Castro-Gomes (2005) nos mostra que a espoliação colonial foi legitimada por um conjunto de concepções que acabou por estabelecer as diferenças entre colonizador/a e colonizado/a.

A proposta de dominação/ subalternização foi um dos pilares da construção da modernidade, marcando a relação dicotômica branco/ europeu/ racional/ civilizado e o outro/ irracional/ não civilizado. Assim, a ideia e a invenção da raça acabaram por operar como dispositivo central no processo de hierarquização dos povos, justificando a violência e a exploração. Foi nesta perspectiva que Anibal Quijano cunhou a denominação 'colonialidade do poder', a partir da relação histórica responsável pela classificação e

2 É oportuno destacar que colonialidade é diferente de colonialismo. Walsh (2009) esclarece que, apesar de relacionados, estes são conceitos distintos. A colonialidade é mais duradoura e envolve as relações de poder que emergem do contexto da colonização europeia e que têm associado dominação/ subordinação, colonizador/ colonizado, apesar da emancipação das colônias. A colonialidade é parte constitutiva da modernidade; é seu lado sombrio, oculto e silenciado (MIGNOLO, 2003), determinando a subalternização e a dependência.

Paulo Melgaço da Silva Junior, Leandro da Conceição Borges 
Adolescentes Negros Moradores das Periferias Urbanas do Rio de Janeiro:

Entre Escola, Gênero, Masculinidades, Raça, Violência e Vivências

reclassificação das pessoas do planeta, levando em conta a categoria 'raça' como forma de controle social e desenvolvimento do capitalismo mundial. Nesse contexto, o colonizado observa seus modos de conhecimento e saberes reprimidos e descaracterizados.

A partir deste eixo, foram cunhadas outras possibilidades de colonialidade: a colonialidade do saber, que, relacionada à geopolítica do conhecimento, estabelece um paradigma de conhecimento universal e racional a partir das produções eurocêntricas e de sua relação com o resto do mundo. Desse modo, outras formas de saber, outros conhecimentos e racionalidades advindas dos povos subalternizados são desqualificadas; e a 'colonialidade do ser', desenvolvida por Torres (2003), que envolve um longo processo histórico de formação de identidades subalternizadas sob a hegemonia de uma herança colonial. Aqui é observada e discutida a não-existência do outro, do colonizado, a partir de sua negação sistemática, de sua inferiorização e desumanização. Desconhece-se a alteridade, e o outro é reduzido ao não-ser, condição que reduz o seu valor.

Contudo, Lugones (2007) acrescentou a estas formas de colonialidade a categoria gênero, buscando chamar a atenção para a importância desta nos processos econômicos e históricos da colonialidade. Ao tensionar a interseção entre as categorias 'raça, gênero e colonialidade', a autora afirma que existem os humanos (o homem branco portador da inteligência e razão, seguido da mulher branca), e os não humanos (negros, índios e outros). Neste aspecto, ela caracteriza o gênero como uma ficção que sustenta a colonialidade do poder e a dominação racial. Só os civilizados são homens e mulheres. Os povos indígenas das Américas e os/as africanos/as escravizados/as eram classificados como não humanos - como animais, incontrolavelmente sexuais e selvagens. Assim, "pensar sobre a colonialidade do gênero permite-nos pensar em seres históricos compreendidos como oprimidos apenas de forma unilateral". (LUGONES, 2014, p. 939).

\section{Quando o Gênero, Sexualidades e Masculinidades entram em Questão}

As relações de gênero devem ser compreendidas como uma dimensão central de nossa vida social, tendo suas dinâmicas formas específicas em contextos coloniais e pós-coloniais. (CONNELL, 2016). Neste sentido, Lugones (2007) afirma que elas são marcadas e estão diretamente relacionadas à colonialidade do poder. Assim, para além das questões de gênero e raça, as sexualidades e masculinidades também podem ser pensadas com base nesse eixo, em que o colonizador (homem, branco, europeu, heterossexual) se vê como superior. Com isso, as outras subjetividades - o outro, o diferente, o colonizado - têm seu imaginário destruído, subalternizado e invisibilizado. ${ }^{3}$

Nesta perspectiva, as masculinidades são configurações de práticas associadas à posição social dos homens, sendo definidas coletivamente na

3 Com isto, não podemos perder de vista que o processo de colonização da América foi bastante generificado, marcado pelo masculino, pela sexualização das nativas, dos negros e das negras. Com efeito, o mesmo aconteceu no Brasil, onde o processo de colonização foi extremamente sexualizado, como podemos verificar desde a leitura da Carta de Caminha, que fala das índias nuas, até posteriormente, com a chegada dos/as negros/as.

Paulo Melgaço da Silva Junior, Leandro da Conceição Borges 
Adolescentes Negros Moradores das Periferias Urbanas do Rio de Janeiro:

Entre Escola, Gênero, Masculinidades, Raça, Violência e Vivências

cultura e sustentadas nas instituições. São, pois, comunidades imaginadas e marcadas por discursos e pertencimentos a determinados grupos, não existindo como estruturas consolidadas de papéis. Não obstante, ainda há uma grande preocupação em se criar regras e normas que integrem (disciplinem) os corpos de homens ao essencialismo biológico e racial, ao passo que as masculinidades tendem a ser construídas e reconstruídas continuamente, desafiando a noção de uma realidade imutável e objetiva na qual se encontrariam inseridas (CONNELL, 2016).

No decorrer deste processo, diversos tipos de masculinidades coexistem e são produzidas simultaneamente, sujeitas aos fluxos estabelecidos pela história, pela cultura e pelas relações de poder delas advindas. No entanto, a masculinidade hegemônica cria uma série de regras e restrições para um efetivo pertencimento a esse grupo, nas quais enfatiza o papel do homem nas relações de poder, ressaltando seus privilégios e deveres nas estruturas patriarcais, e estabelecendo uma hierarquia entre elas. ${ }^{4}$

\section{A Raça como Elemento Identitário e de Exclusão}

É relevante ressaltar que de acordo com Silva et al. (2012) a geografia tem se dedicado a construir a inteligibilidade entre sociedade e espaço, criando caminhos importantes no entendimento entre gênero e seu caráter espacial. Esse fato reforça a necessidade de pensar o processo de construção das masculinidades dos adolescentes negros a partir de suas vivências no espaço das periferias urbanas.

Falar em masculinidades negras é passear por um universo misto de autoestima, subalternização, ressignificações e sofrimentos ao longo dos itinerários existenciais. Desde pequeno, o menino negro aprende a se comportar e a vivenciar as subjetividades impostas pela raça: o gosto pelo esporte, o uso da força. Na escola, descobre que a cor da sua pele é um problema, ao ouvir uma série de brincadeiras e insultos racistas. A noção de não-pertencimento a este espaço é reforçada quando, em contato com os materiais didáticos, sobretudo com o livro didático, não é capaz de se reconhecer, a não ser em posições subalternizadas. Resta a ele, como dispositivo de sublimação, a adoção de algumas expectativas estereotipadas, presentes nos ídolos negros do futebol ou nos cantores de alguns ritmos populares (samba, funk e pagode).

Connell (2000) nos apresenta as masculinidades marginalizadas ou subordinadas como aquelas que não atendem ao modelo dominante de raça e classe social. Essas identidades são construídas com base em estereótipos, e os sujeitos são marcados como abjetos, sem brilho e valores.

Tal processo teve início no momento de classificação e hierarquização das raças. O pensamento colonial separou e racializou o sistema-mundo. Naquele momento, o homem negro foi marcado pelo seu sexo. O seu pênis foi tomado como o referencial para sua raça e marcou as distinções entre homens negros e

4 Destacamos, contudo, que esse é apenas um tipo de masculinidade entre as diversas existentes, não sendo a masculinidade hegemônica, ainda que consolidada, o tipo mais comum em nossa sociedade.

Paulo Melgaço da Silva Junior, Leandro da Conceição Borges 
Adolescentes Negros Moradores das Periferias Urbanas do Rio de Janeiro:

Entre Escola, Gênero, Masculinidades, Raça, Violência e Vivências

brancos, tal como proposto por Charles Lineaus, ao afirmar que a inteligência do homem negro é inversamente proporcional ao tamanho de seu pênis e a sua força. Desta forma, sua virilidade foi animalizada, passando a ser considerado como reprodutor.

Como homem liberto, a masculinidade negra, de acordo com Bhabha (2003), passa a ser marcada pelo medo cultural do negro, figurado no temor psíquico da sexualidade ocidental. No Brasil, este cerceamento ocorre no momento de higienização racial, no início do século $\mathrm{XX}$, quando este e seu pênis potente passaram a serem vistos como uma ameaça aos imigrantes brancos, que estavam chegando para branquear a população brasileira. Nesta ocasião, a exemplo de outras, além de sofrer perseguições, ele foi continuamente desqualificado, sendo considerado vadio. Sua suposta inclinação pela bebida acenava para sua irresponsabilidade e propensão a atos violentos.

O modelo de referência para construção da masculinidade passa, então, a ser o europeu, que, ao fixar os padrões de comportamento social, determina os sujeitos habilitados a serem valorizados como os mais inteligentes e capazes, e, consequentemente, a se tornarem mais bem-sucedidos social e economicamente. Cria-se, assim, um modelo idealizado de masculinidade hegemônica, tendo como referência o homem branco cristão europeu. Em decorrência, todas as masculinidades que não se alinharam ao padrão fixado foram subalternizadas (negros, índios, homossexuais). A masculinidade negra passou, então, a ser desqualificada e apresentada socialmente como sinônimo de fracasso, pois a ela faltariam, segundo a lógica vigente, estudo e inteligência. Seus sujeitos possuíam vínculos empregatícios precários, estando constantemente expostos à violência física e simbólica, sobretudo policial, 0 que faz deste segmento o mais atingido por mortes violentas, até os dias atuais.

Contudo, a falomaquia, ou seja, a metáfora do poder do falo (o pênis simbólico, sempre pronto para lutar contra a dominação que marca todo $o$ processo de separação do sistema-mundo que deu força ao homem colonizador), acabou por ressignificar a construção das masculinidades negras, principalmente nas periferias urbanas do Rio de Janeiro. Nestes espaços, o homem negro absorveu os mitos que o desumanizariam como vantagem positiva, fazendo de seu pênis motivo de força, orgulho e superioridade em relação ao homem branco.

No entanto, todo este processo apresentou imbricações nas dinâmicas familiares, demarcando, a partir da fixação ou mesmo da imposição de algumas características, os padrões de relacionamento a serem considerados. Isto se deu a partir da construção histórica da identidade do homem negro, que, marcada pela hipersexualização e por sua desqualificação, fez com que o homem negro passasse a ser (pre)visto como um chefe de família e pai ausentes.

Não obstante, defendemos que a masculinidade negra se encontra em um meio termo entre a marginalização e a exaltação. À medida que é construída, a partir de práticas discursivas, como identidade subalterna por meio da exclusão, pelo pertencimento a uma classe inferior, a identidade sexual do homem negro também é exaltada pelo modelo hegemônico como detentora de

Paulo Melgaço da Silva Junior, Leandro da Conceição Borges 
Adolescentes Negros Moradores das Periferias Urbanas do Rio de Janeiro:

Entre Escola, Gênero, Masculinidades, Raça, Violência e Vivências

virilidade, sendo este considerado bem-dotado e um reprodutor em potencial.

Frosh, Phoenix e Pattman (2002) afirmam que, na Inglaterra, a masculinidade em garotos negros é localizada na estrutura falocêntrica, posicionando-os como superiores aos garotos de outras etnias em relação aos atrativos sexuais. A partir de pesquisas realizadas (SILVA JUNIOR, 2014; SILVA JUNIOR; CANEN, 2011; SILVA JUNIOR; IVENICKI, 2015), podemos ressaltar a reincidência deste padrão no Brasil, onde a sexualidade, a força e a masculinidade do homem negro são exaltadas e reconhecidas, não só entre a comunidade negra, mas por todos/as, em geral.

Em nosso país, o 'macho negro' parece ser visto como modelo de virilidade, de potência e de dotação sexual. Ele também é construído como ativo, como aquele que está, a todo o momento, pronto para o ato sexual. Contudo, é no ínterim entre os processos de hipersexualização e desumanização que ele se torna mais suscetível à violência. Como nos mostra a música do grupo $\mathrm{O}$ Rappa, 'Todo camburão tem um pouco de navio negreiro', os jovens negros são os que mais sofrem com a violência física e simbólica.

Grande parte das representações hegemônicas sobre os homens negros recaem sobre o nosso corpo, nos hipersexualizando, nos desumanizando, ou seja, destituindo-nos dos prestígios, recursos e prerrogativas de sermos "homens-humanos". O pênis (seu tamanho e desempenho) dá a tônica nas relações entre os homens em geral, mas principalmente entre homens negros e brancos. Se por um lado se cria um aparato representacional deformador em torno da virilidade sexual do homem negro, o rebaixando a uma corporeidade quase animalesca, por outro, isso cria ressentimentos por parte dos homens brancos que veem sua hombridade ameaçada (SOUZA, 2017b, s/p).

$\mathrm{Na}$ comunidade em que desenvolvemos a pesquisa, os homens negros foram classificados como inconstantes no processo de constituição da estrutura familiar, não sendo considerados bons pais, em função da vida sexual promíscua. Neste contexto, é comum que as mulheres que têm filhos com eles acabarem por criá-los sozinhas, tornando-se a base de sustentação da família. Acerca disto, Silva Junior (2014) destaca a fala de uma aluna: "eles têm filhos com uma mulher e criam filhos de outros [...] os deles mesmos ficam por aí". Esta fala foi dita ao se estudar uma fotografia de uma família inter-racial de classe média, formada por uma mulher branca, um homem negro e dois filhos brancos. A aluna em questão destacou que, provavelmente, os filhos não eram dele, e expressou as experiências vividas com homens negros naquela comunidade da periferia de Duque de Caxias.

É com base nas considerações acima que defendemos a importância de conhecermos os estudantes negros, de sabermos o que pensam e como se posicionam como homens. Assim, como parte deste exercício, estaremos apresentando, nas seções seguintes, a escola, os adolescentes e o contexto de pesquisa.

Paulo Melgaço da Silva Junior, Leandro da Conceição Borges 
Adolescentes Negros Moradores das Periferias Urbanas do Rio de Janeiro:

Entre Escola, Gênero, Masculinidades, Raça, Violência e Vivências

\section{A Escola, os Sujeitos e o Contexto do Grupo Focal}

A escola na qual foi desenvolvido este trabalho está localizada no $2^{\circ}$ Distrito do município de Duque de Caxias, na Baixada Fluminense, estado do Rio de Janeiro. ${ }^{5}$ Com aproximadamente 35 anos de existência, a instituição atende a alunos/as compreendidos desde a Educação Infantil ao segundo segmento do Ensino Fundamental. Seu público é composto de moradores e moradoras do bairro e de favelas próximas. É o único órgão representante do poder público na região, que exibe um grande número de igrejas evangélicas, alguns terreiros de candomblé, bares, biroscas, lan houses e pequenos estabelecimentos comerciais (mercados e padarias) para atender à comunidade composta por trabalhadores/as informais, faxineiros/as, empregados/as domésticos/as e desempregados/as. Nestes espaços, a população, pertencente às camadas populares, é socialmente desfavorecida e passa por grandes dificuldades financeiras.

Para a escrita deste artigo, realizamos em uma sexta-feira, dia 2 de junho de 2017, uma roda de meninos negros para conversarmos sobre sexualidades e masculinidades. O encontro foi marcado pela manhã, pois, logo após, o professor pesquisador realizaria um passeio cultural pelo Centro Histórico do Rio de Janeiro com um grupo de alunos. Assim, o grupo formado por quatro alunos chegou à escola por volta das 7 horas da manhã ${ }^{6}$.

Devemos destacar que estas rodas de conversas entre professor e alunos/as naquela escola se dão constantemente, com temáticas variadas. É comum naquela comunidade alunos procurarem professores/as nos quais eles têm confiança para conversar; ou mesmo os/as professores/as provocarem conversas prolongadas com determinados/as alunos/as. Acreditamos que esta seja uma das características das relações construídas nas periferias urbanas (SILVA JUNIOR; MOREIRA, 2010), onde a escola é uma das poucas referências para que os /as jovens possam problematizar algumas questões.

Acreditamos que, enquanto professores/ educadores, devemos proporcionar alguns destes pequenos momentos de desconstrução de verdades essencializadas e cristalizadas pelo senso comum ${ }^{7}$. Por este caminho, apresentamos, de maneira mais detalhada, os adolescentes convidados para a conversa.

Pedro, 17 anos. Um rapaz negro, alto, forte, praticante de todos os esportes

5 Ressaltamos que um dos autores trabalha como professor de Artes nesta instituição pública há aproximadamente 15 anos. Assim, ao longo deste período, tem presenciado diversos discursos de alunos/as em relação aos temas em tela e, com isto, defendido a importância de as escolas problematizarem visões cristalizadas e essencializadas de gênero, sexualidades, masculinidades e raça. (MELO; ROCHA; SILVA JUNIOR, 2013; SILVA JUNIOR, 2014; SILVA JUNIOR; IVENICKI, 2015).

6 Destacamos que todos foram previamente informados da proposta, tendo sido solicitada autorização aos pais para a gravação em áudio da conversa, que intitulamos 'Entre adolescentes negros'. A proposta central era conhecer o posicionamento deles como sujeitos sociais, provocando reflexões sobre alguns dos temas evocados.

7 Defendemos que estes momentos, aqui chamados por nós de pedagógicos, podem acontecer em qualquer espaço no cotidiano escolar, não existindo a necessidade de ocorrerem em uma sala de aula, e muito menos com a turma inteira.

Paulo Melgaço da Silva Junior, Leandro da Conceição Borges 
Adolescentes Negros Moradores das Periferias Urbanas do Rio de Janeiro:

Entre Escola, Gênero, Masculinidades, Raça, Violência e Vivências

propostos na escola. Não tem namorada fixa, e se orgulha deste fato. Veste-se muito bem, procurando estar sempre de cabelo cortado, sempre solícito e com um sorriso no rosto. Estuda na escola desde os 9 anos de idade. Mora na comunidade.

Daniel, 15 anos. Seu corpo desenvolvido não reflete a pouca idade. Um rápido olhar nos mostra um rapaz de 17/18 anos. Trabalha com gesso, auxiliando seu pai. Com o dinheiro que recebe, comprou sua moto. Por causa dela, já enfrentou problemas na região. Também não possui namorada fixa. Estuda na escola desde o $6^{\circ}$ ano.

Thiago, 16 anos. É sobrinho de Daniel. É magro e baixo, sem nenhum atributo físico que chame a atenção como os outros anteriores. Muito brincalhão, destaca sempre que se orgulha em ser negro. Estuda na escola deste os 5 anos de idade.

Lorran tem 15 anos, e a história de sua família chama atenção: o pai é mecânico na comunidade, e possui 29 filhos. Destes, diversos estudam/estudaram na escola, inclusive alguns já estão trazendo seus filhos. Pelo fato de ter várias mulheres, seu pai acaba se tornando o referencial de muitos jovens na comunidade.

Conforme dito anteriormente, a gravação aconteceu na escola, pouco antes de realizarmos um passeio cultural. Como um dos autores é professor dos quatro rapazes há alguns anos, o clima foi completamente informal, sendo as perguntas conduzidas por ele. Na próxima seção apresentamos os trechos da conversa gravada sobre o que é ser "homem negro".

\section{Entre Adolescentes Negros}

Sobre os pais e homens na família que servem como modelo de masculinidade negra, Lorran nos conta: "Meu pai tem 29 filhos. [...] Ele cria 5 em casa. Os outros ele registrou, mas estão com as mães. Ele diz que as mulheres que quiseram pegar barriga dele [...] e que o negro tem que representar, tem que honrar a cor [...] Ele incentiva os filhos homens, mas diz para a gente não deixar vir filhos [...] a gente tem que agradar as mulheres sem engravidar".

As falas dos estudantes permite refletir sobre o processo de construção das masculinidades negras. Conforme Lugones (2014) destacou, o processo de colonialidade acabou por desumanizar o homem negro, principalmente ao animalizá-lo e colocá-lo como sexualmente incontrolável. Esta hipersexualização e associação à vida sexual promíscua (SOUZA, 2017b) acabam por afetar diretamente no modelo de constituição das famílias, principalmente nas periferias urbanas (SILVA JUNIOR, 2014). A ausência do pai biológico como chefe de família é uma constante entre os garotos negros. Os motivos que justificam a ausência podem ser vários, que vão desde a morte ou prisão, ou o simples fato de possuir várias relações, conforme o aluno Lorran exemplificou.

Neste sentido, dos quatro adolescentes em foco, três não conviveram com seus pais biológicos. Lorran é o único que mora e convive com o pai. Contudo, o modelo de pai que ele possui representa a hipersexualização e animalização do homem negro. Conforme Frosh, Phoenix e Pattman (2002); e Silva Junior e 
Adolescentes Negros Moradores das Periferias Urbanas do Rio de Janeiro:

Entre Escola, Gênero, Masculinidades, Raça, Violência e Vivências

Ivenicki (2015) nos mostram, as masculinidades negras são, a partir da estrutura falocêntrica, perceptíveis nas falas de Lorran, em que o pai incentiva os filhos a manterem relações com as mulheres, pois "têm que representar e honrar a cor". Aqui, o negro é visto como o reprodutor (SILVA JUNIOR; CANEN, 2011; SOUZA, 2017b), aquele pronto a satisfazer os desejos da mulher. Contudo, ele se isenta da responsabilidade da paternidade, culpabilizando-a pela gravidez.

Pedro: "Quem me ensinou jogar bola, brincar, foi meu tio [...] ele sempre disse que negro é forte, que não pode apanhar na rua". Thiago: "Meu tio me ensinou a jogar futebol [...] ele dizia que tinha que ser jogador de futebol para ganhar dinheiro e ser rico. Que, quando eu fosse rico, teria muitas mulheres, casa e carro, e ainda ia ajudar a família". Daniel: "Na minha casa, nunca teve esta conversa [...] minha mãe me criou sozinha junto com os meus irmãos [...] depois, o marido dela me chamou para trabalhar com ele, colocando gesso. Eu tinha uns 13 anos, e eles disseram que era para mim não ficar nas ruas".

O gosto pelos esportes e o uso da força fazem parte do universo masculino. (CONNELL, 1995, 2000, 2016) Desde cedo, os garotos são apresentados pelos familiares ao mundo dos esportes e da força. O sonho de mudar de vida por meio dos esportes também é uma constante na vida destes garotos. Alguns familiares e os próprios garotos acreditam que a prática de esportes, principalmente o futebol, pode ser uma possibilidade de construção de futuro.

Ao mesmo tempo, por medo da violência nas ruas, e com a necessidade de obter dinheiro extra, os familiares optam por colocar os jovens, mesmo muito novos, no mercado de trabalho. Assim como o exemplo de Daniel, todos os quatro adolescentes participantes da roda de conversa realizam pequenos trabalhos informais, seja em lava a jato, ou como auxiliares em oficinas mecânicas. Esta opção de introduzir os jovens no mundo do trabalho funciona como uma estratégia para mantê-los ocupados e fora das ruas e, ao mesmo tempo, permite que eles ganhem algum dinheiro para cobrir algumas de suas necessidades, como roupas e saídas de final de semana.

\section{Entre o Neguinho e Negão}

Pedro explicou que "neguinho" é uma forma carinhosa de chamar o amigo: "a gente chama de neguinho aquele que é parceiro". Lorran, por sua vez, comenta que o neguinho também pode ser um desconhecido; é uma forma de se referir ao outro: "nós chamamos de neguinho qualquer um: [...] pode ser um amigo, pode ser um cara na praça". Ser chamado de negão é considerado como um elogio à virilidade (SILVA JUNIOR, 2014; SILVA JUNIOR; IVENICKI, 2011). Assim, se o negão está relacionado diretamente à força, à virilidade, o neguinho, de acordo com os participantes, seria um elogio àquele negro que eles consideram amigo, mas que não atende às características do negão.

Neste sentido, o termo neguinho será sempre utilizado quando estiverem se referindo ao amigo ou colega legal, alegre. É relevante destacar que esta expressão não é atravessada por conotação sexual. Um desconhecido pode ser chamado de neguinho. Contudo, na visão deste grupo, o termo não é depreciativo. Nenhum dos participantes se julgaria inferiorizado pelo grupo caso fosse chamado de neguinho.

Paulo Melgaço da Silva Junior, Leandro da Conceição Borges 
Adolescentes Negros Moradores das Periferias Urbanas do Rio de Janeiro:

Entre Escola, Gênero, Masculinidades, Raça, Violência e Vivências

\section{E as Meninas?}

Lorran relata: "Olha, professor, elas preferem caras de moto, todo pintoso. A gente tem que marcar ponto nas novinhas [...] elas que pedem, e pediu, tem que passar o rodo, senão dizem que a gente é viado". Pedro: "Eu saio com uma menina aí [...] ela acha que é minha namorada, tem 19 anos. Mas não namoro não!!! Estou novo [...] Se estas daqui derem mole, eu pego [...] tenho que deixar minha assinatura, dar meu nome [...] pensa você [...] na praça, a menina chega e você corre [...] ninguém acredita". Thiago: "Namorar pra quê? Tem muita novinha aí dando mole [...] eu fico [...] estou novo para namorar".

As falas dos adolescentes revelam como as masculinidades negras podem ser relacionadas ao processo de colonização (CONNELL 2016; LUGONES, 2007, 2014) e marcadas pela hipersexualização (SILVA JUNIOR, 2014; SOUZA, 2017a, 2017b). Em suas palavras, Lorran nos mostra como o processo de construção das masculinidades heterossexuais está relacionado com a negação da homossexualidade. (SILVA JUNIOR; CANEN, 2011). Em outras palavras, os jovens negros precisam estar prontos para o ato sexual e satisfazer às meninas, porque, do contrário, não serão considerados homens.

A colonização do ser (TORRES, 2003) nos revela como as subjetividades dos sujeitos colonizados foram simplificadas, reduzidas; com isso, surge a preocupação dos adolescentes em atender às necessidades das meninas. $\mathrm{O}$ discurso os construiu como aqueles que estão prontos para o ato sexual (SILVA JUNIOR, 2014).

Ao mesmo tempo, a fala de Pedro reforça o pensamento anterior, ao revelar a necessidade de se ter várias namoradas, de precisar assinar o nome. Este fato pode nos fazer refletir sobre uma das críticas ao homem negro, ou seja, a de que este não se consideraria solidariamente responsável por suas relações e seus desdobramentos, o que inviabilizaria sua participação no processo de construção familiar. Assim, se levarmos em consideração que as masculinidades são cultural e socialmente construídas e afirmadas em grupo (CONNEL 1995, 2000, 2016), os adolescentes vivenciam neste grupo e, certamente, aprendem em outros grupos a necessidade de sair com diversas mulheres.

\section{Força e Violência}

Daniel: "A polícia, os milicos, sempre tratam a gente como bandidos [...] com o dinheiro que ganho, trabalhando com meu tio, comprei uma motinha [...] minha mãe não está deixando eu sair com ela, nem para escola [...] os milicos me seguiram até aqui na escola [...] disseram que roubei [...] minha mãe está com medo". Pedro: "É sempre assim [...] os polícias fazem a mesma coisa, os seguranças também. Eu não brigo em baile na rua [...] só quando os moleques vacilam [...]".

O medo da violência policial se evidencia na fala dos adolescentes. Estes jovens se sentem ameaçados, tanto pelos milicianos, como pelos policiais e seguranças. O sonho de possuir um bem material, ou seja, de comprar a moto, acabou sendo frustrado pelo medo dos milicianos tomarem. O negro acaba sendo associado a diversas subjetividades negativas e, por isso, está mais

Paulo Melgaço da Silva Junior, Leandro da Conceição Borges 
Adolescentes Negros Moradores das Periferias Urbanas do Rio de Janeiro:

Entre Escola, Gênero, Masculinidades, Raça, Violência e Vivências

suscetível à violência..

\section{Sobre Homossexualidade e Sexo com Homens}

Pedro: Olha, professor, [...] vou contar aqui... porque o senhor disse que ninguém vai saber quem sou [...] os moleques aqui sabem [...] eu até já saí com uns viados lá da praça $[. .$.$] , mas eu sou macho [...] sou homem [...] eles$ oferecem um dinheiro [...] querem ser mulher [...] então [...], mas eu parei”. Daniel: "Eu trabalho por isso [...] não preciso do dinheiro deles". Pedro interrompe a fala: "Mas já deixou mamar"! Daniel: "Mas não sou viado não! Sou macho"!

A hipersexualização do homem negro tende a enfatizar sua heterossexualidade (MELO, ROCHA; SILVA JUNIOR 2013; SILVA JUNIOR, 2014), dificultando, assim, que homens negros possam falar sobre suas vivências que se distanciem deste padrão. Neste sentido, ainda que possam admitir ter tido contato íntimo com outros homens, eles não entendem que estas relações ocasionais com pessoas do mesmo sexo os caracterizem como homossexuais.

A separação entre o ativo e o passivo, ou seja, entre quem deixa executar o ato e quem o executa, seria a linha divisória entre as definições de heterossexual e homossexual. Em outras palavras, eles não consideram que o fato de fazer sexo por dinheiro ou atuar como ativos em uma relação sexual com outro homem seja uma possibilidade de perderem a masculinidade. De acordo com a fala de Pedro, são os outros que "querem se tornar mulheres".

A incontinência sexual do homem negro, reforçada pelo discurso colonial (BHABHA, 2003; LUGONES, 2007) e aliada à oferta de dinheiro, acaba por colocar os adolescentes neste jogo de sexualidades. Este fato pode acabar por subalternizar a masculinidade homossexual (CONNELL, 2000), tornando o outro passível de sofrer violência física e simbólica.

\section{Sobre Camisinha}

Lorran: "Eu uso sempre [...] tem que usar". Daniel: "Eu gosto de pele na pele [...] Quando a menina é certinha, eu não uso, só quando ela exige [...], mas com estas do baile, eu uso". Pedro: "camisinha pra quê? O negócio é pele na pele".

A hipersexualização dos adolescentes acaba por colocá-los em situação de vulnerabilidade. Eles aprendem, desde muito jovens, que ser homem significa se relacionar simultaneamente com diversas mulheres. Com isso, ao se colocarem predispostos às relações sexuais desprotegidas, eles acabam sujeitos à paternidade indesejada e a contrair doenças sexualmente transmissíveis.

Ao longo da roda de conversa, e pelo relato das práticas previstas e realizadas a partir do Projeto Político-Pedagógico da escola, pudemos atestar que os adolescentes conhecem a importância e a função dos preservativos, tanto para a prevenção de gravidez, como para a prevenção de doenças. No entanto, se levarmos em consideração a afirmativa de Pedro, que praticou sexo com outros homens, correlacionando-a com a dificuldade de se garantir com que jovens da sua faixa etária e classe social incorporem o uso de preservativos

Paulo Melgaço da Silva Junior, Leandro da Conceição Borges 
Adolescentes Negros Moradores das Periferias Urbanas do Rio de Janeiro:

Entre Escola, Gênero, Masculinidades, Raça, Violência e Vivências

as suas relações cotidianas, se observa por parte dos jovens pouca preocupação com as questões relacionadas à saúde preventiva e ao exercício consciente da sexualidade. Deste modo, fica evidente a necessidade das escolas, principalmente das localizadas em periferias urbanas e com predomínio de alunos/ homens negros, em desenvolver programas de orientação sexual, discutindo, assim, a importância do uso de preservativos como um dispositivo de cuidado com eles mesmos.

\section{Conclusões}

A epígrafe que emoldura o texto revela nossa angústia em relação à situação dos homens negros da periferia urbana - a carne mais barata do mercado, a que está sempre em oferta e que pouco ocupa os bancos das escolas. Assim, a questão central que permeou este artigo foi a necessidade de se conhecer como as masculinidades negras da periferia urbana são construídas a partir das vivências dos adolescentes. A compreensão do espaço foi de grande importância para percebermos a potencialidade das periferias pobres para ampliar as condições de vulnerabilidade dos adolescentes negros frente às questões sociais.

Nestes termos, discutir a vulnerabilidade destes adolescentes negros frente a violência, à hipersexualização e à exposição de seus corpos se mostra como um imperativo de fundamental importância. Estamos conscientes de que os conceitos relacionados às masculinidades são amplos e estão diretamente atravessados pela raça, classe social, entre outros marcadores. Conforme apresentado por Silva Junior (2014), em algumas periferias urbanas, o homem negro é construído a partir de sua estrutura falocêntrica. Com isso, outros aspectos de suas subjetividades tendem a ser ignorados, o que, em alguns casos, podem vir a provocar futuros desvios de comportamento, tais como a violência contra a mulher, a homofobia, a lesbofobia, entre outros delitos associados ao exercício patológico da sexualidade. Connell (2016) destaca a importância que deve ser dada aos processos educativos para a sexualidade, uma vez que, segundo ele, estes jovens de hoje serão, no futuro, chefes de família, esposos, companheiros e responsáveis pela formação de novos jovens. Assim, problematizar a dinâmica dos futuros relacionamentos significa a busca pela compreensão dos futuros interesses dos homens (meninos) na igualdade de gênero.

Por outro lado, é importante destacar que o cotidiano de se "ser adolescente negro" nas periferias urbanas de Duque de Caxias se articula de modo completamente distinto de qualquer outro espaço elitizado. Isto significa dizer que os discursos que estes adolescentes negros produziram pertencem a um momento específico, social e territorialmente situado. Entendemos que, caso eles estivessem inseridos em outros grupos identitários e interagindo com outros sujeitos, apresentariam outras falas e respostas às indagações propostas.

Consideradas estas questões, cabe destacar que a roda de conversa com o grupo de adolescentes negros evidenciou, em um primeiro momento, os processos de (des)humanização do homem negro, em uma tentativa de descolonizar o pensamento que reduz o homem negro ao pênis e a sua sexualidade. Por conseguinte, as respostas obtidas, ao se trazer para as 
Adolescentes Negros Moradores das Periferias Urbanas do Rio de Janeiro:

Entre Escola, Gênero, Masculinidades, Raça, Violência e Vivências

discussões textos representando as múltiplas possibilidades destes adolescentes em se construírem como sujeitos, atestaram a sua relevância, bem como a necessidade em se investir nos processos de universalização de sua oferta, o que defendemos através da articulação e implantação de políticas educacionais em gênero e saúde, voltadas especificamente para estes jovens.

Para concluir, gostaríamos de enfatizar que este artigo, como ato de problematização, pode vir a contribuir para a compreensão da juventude e para os estudos no campo da educação, favorecendo a aproximação entre a escola, os jovens e as questões próprias do gênero masculino.

\section{Referencias}

BHABHA, H. O local da cultura. Belo Horizonte: UFMG, 2003.

CASTRO-GÓMEZ, S. Ciências sociais, violência epistêmica e o problema da 'invenção do outro'. In: LANDER, E (Org). A colonilidade do saber: eurocentrismo e ciências sociais. Perspectivas latino-americanas. Buenos Aires: CLASCO, 2005, p. 169 - 186.

CERQUEIRA, Daniel et al. Atlas da Violência. Brasília, DF: IPEA/FBSP, 2017. Disponível em: <http://www. ipea. gov. br/atlasviolencia/arquivos/downloads/8623-170602atlasdaviolencia2017.pdf $>$. Acesso em 29 novembro de 2017.

CHIMIN JUNIOR, A. B. O espaço como componente da vulneralidade dos adolescentes do sexo masculino em conflito com a lei para a conduta infracional. Terr@Plural, v. 3, n.1, p. 41 - 53, 2009.

CONNELL, R. W. Políticas de masculinidade. Educação e Realidade, v. 20, n. 2, p. $185-206,1995$.

CONNELL, R. W. The men and the boys. Berkeley: The University of California Press, 2000.

CONNELL, R. W. Gênero em termos reais. São Paulo: nVersos, 2016.

FROSH, S. ; PHOENIX, A. ; PATTMAN, R. Young masculinities. New York: Palgrave, 2002.

GOMES, F. B.; SILVA, J. M. Necropolíticas espaciais e juventude masculina: a relação entre a violência homicida e a vitimização de jovens negros pobres do sexo masculino. Geousp - Espaço e Tempo, v. 21, n. 3, p. 703 - 717, 2017.

JORGE, S. ; YUKA, M. ; CAPELLETTE, W. A carne. Intérprete: Elza Soares. In: ELZA SOARES. Do cóccix até o pescoço. Salvador: Maianga, p2002. 1 CD. Faixa 6.

GONDIM, S. M. G. Grupos focais como técnica de investigação qualitativa: 
Adolescentes Negros Moradores das Periferias Urbanas do Rio de Janeiro:

Entre Escola, Gênero, Masculinidades, Raça, Violência e Vivências

desafios metodológicos. Paideia, v. 12, n. 24, p. 149 - 161, 2003.

LUGONES, M. Heterosexism and the colonial/modern gender system. Hypatia: a journal of feminist philosophy, v. 22, n. 1, p. 186 - 219, 2007.

LUGONES, M. Rumo a um feminismo descolonial. Estudos Feministas, v. 22, n. 3, p. 935-952, 2014.

MIGNOLO, W. Histórias globais projetos locais: colonialidade, saberes subalternos e pensamento liminar. Belo Horizonte: UFMG, 2003.

MIGNOLO, W. El pensamiento decolonial: desprendimiento y apertura. Un manifiesto. In: CASTRO GÓMEZ, S. ; GROSFOGUEL, R. (Org. ). El giro decolonial: reflexiones para uma diversidad epistémica más allá del capitalismo global. Bogotá: Universidad Javeriana-Instituto Pensar/Universidad Central-IESCO /Siglo del Hombre Editores, 2007, p. 25 46.

MELO, G. C. V. ; ROCHA L. L. ; SILVA JUNIOR, P. M. Raça, gênero e sexualidade interrogando professores (as): perspectivas queer sobre a formação docente. Poiesis, Santa Catarina, v. 7, n. 12, p. 237 - 255, 2013.

MOITA LOPES, L. P. Identidades fragmentadas: a construção discursiva de raça, gênero e sexualidade em sala de aula. Campinas: Mercado das Letras, 2002.

SILVA, J. et al. Espaço, masculinidades e adolescentes em conflito com a lei. Geo UERJ, v. 1, n. 23, p. 136 - 166, 2012.

SILVA JUNIOR, P. M.; CANEN, A. Garotos. com - quando as visões de heteronormatividade e masculinidade hegemônicas são colocadas em questão: um olhar sobre o processo de construção das masculinidades entre garotos do $5^{\circ}$ ano. In: SEMINÁRIO CORPO, GÊNERO E SEXUALIDADE, 5., 2011, Rio Grande. Anais... Rio Grande: FURG, 2011.

SILVA JUNIOR, P. M.; IVENICKI, A. Sou negão com prazer! Em busca de possibilidades de problematizar o processo de construção das masculinidades negras. In: SEMINÁRIO ENLAÇANDO SEXUALIDADES: MORALIDADES, FAMÍLIA E FECUNDIDADE, 4. , 2015, Salvador. Anais... Salvador: UNEB, 2015. Disponível em: <http://www. uneb. br/enlacandosexualidades/files/2015/07/NEGAOCOM-PRAZER. pdf >. Acesso em: 23 nov. 2017.

SILVA JUNIOR, P. M. ; MOREIRA, A. F. Periferias, sexualidades e educação para a sexualidade: desafios para as práticas curriculares. In: SOBREIRA, H. G. (Org. ). Educação, cultura e comunicação nas periferias urbanas. Rio de Janeiro: Lamparina, 2010. p. 21 - 39.

Paulo Melgaço da Silva Junior, Leandro da Conceição Borges 
Adolescentes Negros Moradores das Periferias Urbanas do Rio de Janeiro:

Entre Escola, Gênero, Masculinidades, Raça, Violência e Vivências

SILVA JUNIOR, P. M. Quando as questões de gênero, sexualidades, masculinidades e raça interrogam as práticas curriculares: um olhar sobre o processo de co/construção das identidades no cotidiano escolar. 2014. Tese (Doutorado em Educação) - Universidade Federal do Rio de Janeiro, Rio de Janeiro.

SOUZA, H. R. da C. Homens negros intelectuais: paradoxos e potências. Justificando direito: mentes inquietas pensam direito, São Paulo, 30 out. 2017a. Disponível em: $<$ http://justificando.cartacapital.com.br/2017/10/30/homens-negrosintelectuais-paradoxos-e-potencias/> . Acesso em 20 novembro de 2017.

SOUZA, H. R. da C. Como é ser um homem negro no Brasil? Justificando direito: mentes inquietas pensam direito, São Paulo, 3 jul. $2017 \mathrm{~b}$. Disponível em: < http://justificando. com/2017/07/03/como-e-ser-um-homemnegro-no-brasil/>. Acesso em 20 novembro de 2017.

WALSH, C. Interculturalidad y (de)colonialidad: perspectivas criticas y políticas. In: CONGRESSO ARIC, 12. , 2009, Florianópolis. Conferência inaugural... Florianópolis: UFSC, 2009.

YUKA, M. Todo camburão tem um pouco de navio negreiro. Intérprete: $\mathrm{O}$ Rappa. In: O RAPPA. O Rappa. Rio de Janeiro: Sony, p1994. 1 CD. Faixa 3.

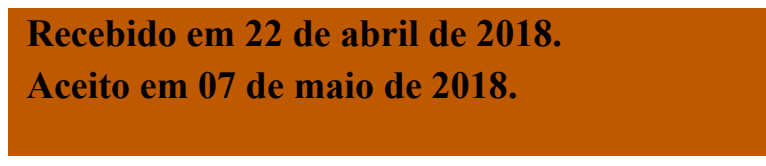

Paulo Melgaço da Silva Junior, Leandro da Conceição Borges 